\title{
DENTAL PRODUCTS AND SERVICES
}

Please send product news information and images to Kate Quinlan at the $B D J$, Nature Publishing Group,

The Macmillan Building, 4-6 Crinan Street, London, N1 9XW. Product news is provided as a service to readers

using text and images from the manufacturer, supplier or distributor and does not imply endorsement by the $B D J$.

Normal and prudent research should be exercised before purchase or use of any product mentioned.

\section{FOR ALL YOUR ORAL HEALTH PRODUCTS}

If you are looking for first-class oral health products for your practice, then look no further than Wrights. Wrights has a wide range of quality dental health solutions at competitive prices, both for chairside use and for patients to use as part of a daily routine.

For the practice, Wrights provides a number of acid neutralisers, chairside mouthwashes, prophylaxis pastes and whitening solutions.

For your patients, the supplier offers toothbrushes and toothpastes from popular brands including Aquafresh, Colgate, Curaprox, Macleans, Oral-B, Sensodyne, Tandex, TePe and Wisdom. Other quality products available include dental floss, interdental brushes, mouthwashes and denture solutions.

With regular discounts available, year-round free next day delivery and unbeatable customer service, go to Wrights for your oral health products.

Call Wrights on 0800668899 or visit the easy to navigate website at www.wright-cottrell.co.uk.

\section{THE SHADE SELECTION SYSTEM OF CHOICE}

GC's new Essentia seven shade universal composite range enables clinicians to break free from conventions and eye-match intuitively.

Essentia is a high quality composite system with excellent handling properties that make it easy to place and sculpt. The GC composite brushes are an excellent aid to sculpting the material. With only seven shades, the technique of selecting a shade based on value rather than hue and chroma is unconventional. The shade selection is made easier by taking a preoperative photograph with a polarising lens of the tooth with a small piece of the composite in situ to confirm the choice. The posterior composite universal shade has very good aesthetics for a single shade too.

For further information contact GC UK Ltd on 01908 218999, email info@gcukltd.co.uk or visit www.gceurope.com.

\section{SPONGES THAT HOLD 40-50 TIMES THEIR WEIGHT IN BLOOD}

Haemostasis is crucial for controlling blood flow during dental interventions. HYGITECH haemostatic sponges are made of high quality gelatine, highly processed and purified, offering good adhesion to the bleeding site, promoting the formation of the fibrin network essential to efficient coagulation. Resorption is complete in 3-4 weeks.

As a macro-porous sponge, HYGITECH haemostatic sponges are insoluble in water with a rapid absorption capacity, equivalent to 40-50 times their weight in blood or other liquids. HYGITECH sponges are easy to use and malleable; they are combined with an antibacterial agent; and they can be cut to fit the bleeding area. They are delivered in single sterile blister packs.

HYGITECH is a German manufacturer and distributor of specialised dentistry products, from dental instruments to surgical preparation to sterilisation.

Visit hygitech.uk or telephone 02038081110.

\section{INCREASE YOUR INCOME FROM PRIVATE HYGIENE TREATMENT}

Denplan is rolling out its new hygiene payment plan nationwide. This follows a successful trial that has been running in Scotland since January 2015. Hygiene Plan is a simple, non-insurance-based payment plan that can be used in mixed, private or NHS practices. It will support dental practices that would like to increase their income from private hygiene treatment. It is also an easy way for patients to spread the cost of their hygiene treatments with a hygienist at a practice.

By using Hygiene Plan, practices can eliminate unwanted white space from the diary, generate additional income and fully utilise experienced hygienists, therapists and treatment co-ordinators to create and deliver hygiene programmes for patients.

Hygiene Plan will help patients enjoy that 'just cleaned' feeling without having to worry about the cost, and includes the provision of preventive dental advice. Practices can enjoy the benefit of a more regular private hygiene income with patients that are likely to attend more regularly.

Further information about Hygiene Plan is available at www.denplan. co.uk/dentists/hygiene. 